Article

\title{
Intention of tourism practitioners to behave actively prevent COVID-19 in Zhangjiajie
}

\author{
Hongjiu Tang ${ }^{1,2 *}$ Zhaoyin Liu ${ }^{2}$ \\ 1.School of Geography and Planning, Sun Yat-Sen University, Guangzhou 510275, China. \\ 2.College of Resources \& Environment, Hunan Agricultural University, Changsha 410128, China. \\ * Correspondence: tanghj5@mail2.sysu.edu.cn
}

\begin{abstract}
Background: This study examines the intention to behave actively prevent COVID-19 among local tourism practitioners by adopting an empirically validated norm activation model (NAM) of Schwartz and merging it with the Expectancy theory of Vroom; (2) Methods: The study aims to develops a theoretical framework for understanding the formation and predicting the change of personal protective intention to prevent COVID-19. Based on 514 valid responses from the field surveys; (3) Results: The author develops the refined model including 7 constructs and 26 observational items, and the results showed that the refined model has enjoys a better predictive accuracy of protective intention than the original NAM; and (4) Conclusions: The intention of preventing COVID-19 should needs wider public support and advocacy, and recognizing the change rule of improving behavioral intentions of preventing COVID-19 to maintain the safe tourism image of tourist attractions in Zhangjiajie is also benefits for local tourism practitioners.
\end{abstract}

Keywords: Tourism livelihood income; prevent COVID-19; protective intention; merged model; local tourism practitioners

\section{Introduction}

Zhangjiajie, a world renowned chinese tourism destinationin, has many high-quality tourism resources. And this city has chosen tourism as its leading industry, the city's tourism revenue in 2018 was $\$ 6.157$ billion, accounting for $70.37 \%$ of the city's total regional GDP in 2018 (data from the 2018 statistical bulletin on national economic and social development of Zhangjiajie, China. The average value of the central parity rate of RMB against the US dollar was 6.617 in 2018). So, it is a typical tourist city with many locals rely on tourism as an important source of personal livelihood incomes. But on the end of January 2020, a pandemic called COVID-19 suddenly affected most parts of China, and tourism in many tourist cities was suddenly stopped by the government for the safety of people's lives. Therefore, leisure, sightseeing and other tourism activities in Zhangjiajie were stopped and strongly restricted. These restrictions would further affect the local tourism practitioners' tourism livelihood incomes, drive them to face with increasingly difficulty of obtaining the subsistence income that family members need to survive.

Under the pressure of reduced livelihood income, many tourism participants around the tourism destinations attempt to maintain a safe tourism image after COVID-19 was effectively controlled, in order to restore the pre-epidemic tourism order. In general, the tourist city in China are mainly managed by the government's strong administrative capabilities. After the Chinese government's achieving staged success with preventing COVID-19, the government was authorized some tourist attractions in Zhangjiajie to carry out scientific resumption activities for local tourism participants coming back to work. However, these resumption measures require local tourism practitioners to act as grassroots execution forces to implement. What's more, the important guarantee in this resumption measures are the practitioners' protective intention to prevent COVID-19, and their intentions are the key force in achieving recovery goals. But some practitioners 
have no scientific understanding the harm of COVID-19 towards tourism at the beginning, which caused local tourism practitioners were not united in time to take effective measures with carrying out resumption for local tourism industry. And this problem affects the sustainable livelihood of local resident, so it is urgent to carry out concrete actions to maintain a safe tourism image and eliminate the psychological fear of foreign tourists as early as possible. However, the relationship between tourism livelihood of local tourism participants and personal safety of tourists have often been debated by academics, practitioners, and policy makers. Only if practitioners can guarantee their own health and safety, can the local tourism industry maintain a normal operation order. At the same time, pandemic prevention safety for foreign tourists can also be guaranteed. Although the research on reducing the negative impact of tourism mainly comes from scientific research departments and public management institutions. To make clear how to effectively improve the tourism practitioners' protective intention to prevent COVID-19. It is necessary to study seriously how factors affecting the intention of tourism practitioners and the law of their changes. Mbaiwa and Stronza found that if local tourism practitioners derive benefits from city tourism, they will be obliged to maintain local tourism image sustainably, and they will show more positive personal protective intention[1]. Therefore, the aim of this study is to examine a scientific theoretical framework on the basis of various existing theories and contexts related to intention, then explain that local tourism practitioners' change rule of personal protective intention in a typical tourist city under the impact of COVID-19.

From the above introduction, it can be inferred that local tourism practitioners may not only be a demonstration force in the preventing COVID-19, but also a potential transmitter of the virus. Therefore, it is necessary to study the factors influencing the protective intention of tourism practitioners in or around the tourist attractions. In tourism research, many research achievements are absorbed in the negative effects of epidemics on the macro aspects of economy, transportation, public security, etc., lack of micro-level studies on the emotional psychology of tourism participants' behavior intentions of pandemic preparedness. Meanwhile, city tourism researches often focused on the aggregate effect of different public behaviours. As a public power, local tourism practitioners have an obvious aggregate influence on the development of city tourism. So, the acceptable consensus of sustainable urban tourism should adopt the micro behaviour intentions of practitioners' daily tourism practice into account. Seetanah aggregated the dynamic impact of public actions on the economy. Specifically considered beneficial tourism behaviour for island economies may have comparatively higher growth effects [2]. In this study, local tourism practitioners are the main constituents of the working population of city tourism in Zhangiajie. This study focuses intention of local tourism practitioners on behave actively prevent COVID-19 with a broader perspective. Intention of actively preventing pandemics are not necessary to be relate with specific tourism services or adjustment of tourism products. But personal protective intention of practitioner in the tourist attraction can make a significant contribution to the improvement of psychological security for tourists.

In the early study of behaviour on the pandemic preparedness, social theoretical models based on awareness, attitude, and morality towards maintaining a safe tourism image have been widely used by researchers. It led to many governments attempting to raise public awareness on the safe and hygienic issues. Unfortunately, scholars found that this approach is ineffective later. The study of proactive protective intentions is mainly carried out from two aspects: altruism and self-interests. Tourism researchers who think that responsible behaviour has prosocial motivation usually adopt theory based on ethics, such as Schwartz's norm activation model (NAM) [3] or Stern's introduced value-belief-norm theory $(\mathrm{VBN})[4]$. On the other hand, some researchers think that proactive protective intentions are driven by their own interests. It is also based on a good expectation of future benefits that local tourism practitioners conduct maintaining a safe tourism image under the impact of COVID-19 [5]. Theory of self-interest is based on the premise that behaviour is driven by desirable outcomes or ideal rewards. Zhang further point out that the best approach is to mix the two aspects[6]. Keshavarz \& Karami found attitude - intention gap among tourism practitioners of different regions. Local tourism practitioners usually have a higher awareness of protective 
behaviour [7]. Tourism participants from nonlocal are less inclined to take proactive actions than local participants. All in all, local tourism participants who are closely related to the development of tourist city and their livelihood income will show a more concerned attitude with the image construction of tourist attractions.

Therefore, this study is only aimed at local tourism practitioners in the tourist city. Theoretically, local tourism practitioners should show a significant attitude to protective intention. Another advantage of adjusting the sample populations is that this study paid close attention to the changes of theoretical framework, while samples made up of very consistent members will help to reduce some potential model errors influenced by other mediators. Peng pointed out that in general, the evolution and characteristics of personal protective intention in the tourist city tend to choose large-scale local tourism practitioners [8].

All in all, the study was designed to specifically local tourism practitioners to represent overall tourism practitioners affected by COVID-19 in Zhangjiajie. This study attempts to fulfill the gap of attitude and intention under the impact of COVID-19 by merging Schwartz' norm activation model and Vroom's Expectancy theory, to study the change rules of local tourism practitioners' protective intention in the tourist city with a relatively single tourism industry.

\section{Literature review}

\subsection{Personal protective intention of local tourism practitioner}

The term "personal protective intention" includes a wide range of behaviours, which can be interchanged with other words, such as personal protection behavior, safety prevention behavior, and health prevention behavior. This study adopts Schwartz's definition of personal protective intention, which it discusses any behaviour that protects tourism operation order in daily work or in natural environment or in outdoor environment activities to minimize the negative impact of COVID-19 towards foreign tourists and sustainable development for local tourism[9]. These daily proactive protection behaviours include activities such as wearing masks, keeping enough distance, regularly disinfecting the facilities, and controlling the number of tourists. This study measures personal protective intention of local tourism practitioner in the process of implementing tourism resuming policy in the tourist city. Behavioural intention, simulated by the final construct is adopted from previous widely accepted research achievements. These measurement items include giving priority to accept the guidance of pandemic prevention experts, sacrifice my rest time to promote construction of tourism health facilities, persuade others to cooperate with the staff to maintain a safe tourism image, spend more money to improve the tourism service facilities, learn relevant pandemic prevention skills and knowledge, etc.

Previous studies have found that gender, age, social background, income level, education, and other factors can affect individuals' proactive protective attitude and intention. As mentioned earlier, local tourism practitioners empirically show a higher positive protective attitude in tourism practice because of earning a living from tourism. Theory used in this study measures individual protective intention in the process of maintaining the tourism attractions order, and it is found to be an important predictor of awareness and norms [10]. Because of their emotional bond between humans and the tourist attractions, the degree of performance of tourism participants, including awareness and norms, may vary.

$\mathrm{Yu}$ et al found that if people feel more connected to the local socio-economic development, they are inclined to show a more positive personal responsibility behaviour [11]. Onwezen \& Bartels also found that practitioners who have a positive emotion of belonging to tourism are more inclined to engage in friendly behaviour towards tourists [12]. Agliardi E \& Agliardi R point out some respondents linked protective behaviour to time costs and higher spending constraints, although most of them showed better awareness their hazards of the pandemic and more positive attitudes of preventing COVID-19 [13]. Olya and Akhshik also consider that the barriers of proactive protection behaviour, including money cost, emotional input and awareness of responsibility[14]. In view of the background of this study, money cost and responsibility consciousness may explain the personal protective intention of local tourism practitioners in tourist city. Under the pressure of hard life 
caused by the impact of the pandemic, the economic benefits brought by their own pandemic prevention will be given priority.

\subsection{Norm Activation Model}

Schwartz originally developed the Norm Activation Model (NAM) involves altruistic behaviour. "Personal norms" are the core element of this model, he states that the "personal norms" are described in this way "as feelings of moral obligation not as intentions" [3]. The framework of the model aimed to put forward a scientific understanding of individual supportive attitude in the context of environmentalism context. The personal attitude of the public is now regarded as one of the key powers to solve these social issues. The problem of public proactive protection is a large-scale problem, which needs to be solved by social movements. The public movement of the government 's tourism reinstatement policy is a progress of widespread change process that enterprises, organizations, individuals, and activists must make in order to realize the goal of diminishing the adverse impact of human-beings towards the sustainable development of tourism. These personal norms are used in the NAM to predict individual protective intention, which are influenced by two factors: the feeling of responsibility for performing the specific behaviour [3], and the awareness that performing the specific behaviour. A part of studies interprets NAM as a mediator model, and other part of studies interpret it as a moderation model. Researchers who consider NAM as a mediator model suggests that awareness of consequences influences norms through ascribed of responsibility. Researchers who consider NAM as a moderation model suggests that the impact of norms on behaviour is moderated by awareness of consequences and ascribed of responsibility. This study deems the NAM as a mediator model, and we interpreted that tourism participants should be aware the consequences of protective intention before they feel responsible for it under spread of COVID-19. Then, feelings of environmental responsibility will activate personal norms, and these norms induce one's protective intention[12]. Although effective pandemic preparedness need most of groups to be involved, Michel and Moser considered that the most critical group was the local tourism practitioners, rather than practitioners from other places [15]. Hopper agreed with their studies that to realize some government goals, it is indispensable to change the norms and intention of local tourism participants towards ordinary foreign tourists [16]. Local tourism practitioners have the right to earn their livelihood income from tourist attractions, that is, so-called "the right to economic benefits of tourism operations".

According to NAM theory, personal protective intention can be divided into four components: awareness of consequences, ascription of responsibility, personal norm, and intention of behaviour [3]. Based on the limited scope of the study, only activities in the collectively-owned field or daily tourism practice are analyzed and discussed. Schwartz considered the four basic components are relevant to an ideal cross situational goal with different importance as protective intention requirements in daily practice of individuals or other social entities[3].

Awareness of hazardous consequence (AHE) is the first constructs in the NAM framework under spread of COVID-19, which it refers to the awareness that scientifically wearing masks, maintaining sufficient distance from others, and fulfilling measures of pandemic preparedness to reduce the damage to the tourist image of the destination[4]. Personal awareness is often influenced or improved by the types of collective views and conclusions[3]. Awareness of hazardous consequence have been widely concerned by various of harms, and its relationship as a predictor of protective attitude is often supported by empirical evidence. Schwartz and Boehnke explained that awareness of consequence constructs are complex and can be composed of many variables[3].

Ascription of hazardous responsibility (AHR) is the responsibility that individuals' behaviour can reduce or exacerbate the potential negative impact of consequences[18]. Montada and Kals found that the attribution of responsibility with earning livelihoods income is the biggest influencing factor for local tourism practitioners to actively support the restoration of tourism [19]. Although the relationship between all the variables of NAM often produces good statistical results, compared with other theories, the predictive ability still has problems. Han(2014) found that 
ascription of responsibility in norm activation model had unsatisfactory predictive power in the rational behavior of some public activities[20].

As the next construct, personal protective norm (PPN) are considered a social rule guiding how individuals should comply and are restricted by ascription of responsibility [9]. Kaiser and Bogner (2005) found that norm activation theory has higher predictive power than value-belief-norm theory in the protection behaviour of specific interviewers [21]. Gnoth (1997) subdivide tourism motivation according to personal norm. Their findings highlight the potential for segmentation and measurement of changes in culture, and personal norms are sensitive to the use of cultural interpretation [22] .

At the end of this cause-effect chains is the last construct of the study examines the intention of preventing COVID-19 (IPC). Although we only measures individuals' intentions, some researchers have considered that it is an important indicator of protective behaviours. These individuals' intentions are assumed to be motivated by personal norm, which are identified as some unshirkable obligation to carry out proactive protective behaviours, and the name of the component is used interchangeably[23]. On the whole, awareness of consequences, ascription of responsibility and personal norm are the three influence factors constructs of the norm activation model proposed by Schwartz, they are designed to effectively predict personal intention of behaviour [3]. This framework is often empirically verified by many researchers[18,24]. Definitions of the main terms have been summarized in Table 1. The causal chain of the norm activation model can be viewed as follows: AHE $\rightarrow$ AHR $\rightarrow$ PPN $\rightarrow$ IPC, in view of these analysis and evidences, the following hypotheses are proposed (H1-H3):

H1. Awareness of hazardous consequence has a positive effect on ascription of hazardous responsibility.

H2. Ascription of hazardous responsibility has a positive effect on personal protective norm.

H3. Personal protective norm has a positive effect on local tourism practitioners' intention of preventing COVID-19.

Table 1. summarizes the definitions of each construct.

\begin{tabular}{|c|c|}
\hline variable & definition \\
\hline $\begin{array}{l}\text { Awareness of hazardous } \\
\text { consequence (AHC) }\end{array}$ & $\begin{array}{l}\text { "awareness that the current state of hazardous event will pose a real } \\
\text { threat to other tourists, relevant staff and public order." [3] }\end{array}$ \\
\hline $\begin{array}{l}\text { Ascription of hazardous } \\
\text { responsibility (AHR) }\end{array}$ & $\begin{array}{l}\text { "personal protective actions initiated by individuals or organizations } \\
\text { could avert these long-term or short-term negative consequences." [3] }\end{array}$ \\
\hline $\begin{array}{l}\text { Personal protective norm } \\
\text { (PPN) }\end{array}$ & $\begin{array}{l}\text { "The feelings of a proactive particular action that is morally or ethically } \\
\text { considered to be obliged to do or not to do." [3] }\end{array}$ \\
\hline $\begin{array}{l}\text { Intention of preventing } \\
\text { COVID-19 (IPC) }\end{array}$ & $\begin{array}{l}\text { "any actions that protect the individual or minimize the negative impacts } \\
\text { of hazardous events in either general daily practice or specific outdoor } \\
\text { settings under COVID-19" [9] }\end{array}$ \\
\hline Valence (Val) & "value the individual personally places on praises or rewards" [5] \\
\hline Instrumentality (Ins) & $\begin{array}{l}\text { The perceived possibility of fulfillment, that good effort and performance } \\
\text { may lead to achieve the desired outcome. [5] }\end{array}$ \\
\hline Expectancy (Exp) & $\begin{array}{l}\text { "the perceived probability of doing one's best to achieve good } \\
\text { performance or results." }[5]\end{array}$ \\
\hline
\end{tabular}

$\mathrm{AHE}=$ Awareness of hazardous consequence,

AHR =Ascription of hazardous responsibility,

$\mathrm{PPN}=$ Personal protective norm,

IPC =Intention of preventing COVID-19,

Val=Valence,

Ins= Instrumentality

Exp=Expectancy.

2.3 Negative effects of COVID-19 and Expectancy theory 
The spread of COVID-19 is a kind of hazardous events that had a severe negative impact on tourism[25]. However, a new measurement scale was proposed by Catton and Dunlap for these changes in the process of lifestyles and individuals' activities[26]. Dunlap et al. explain the reasons why human beings take actions to maintain the image and order of tourism in tourist cities that residents need to restore normal social order for earning their livelihood incomes. Therefore, local tourism participants have the right to adapt and implement the policies and measures recommended by the government [27]. Bear believes that, compared with protectionists, social researchers need to assess the public's view of the relationship between the livelihoods of local tourism participants and the sustainability of tourism destinations, thus proving that the adoption of public actions in a given region is reasonable and scientific [28]. National resuming work measures after COVID-19 is designed according to the types of values, which it can predict the expectation of local tourism participants for restoring the tourism order of tourist attractions [18]. In the context of city tourism under the negative impact of pandemics, Westerberg et al. used NAM to explore the investment and altruistic behaviour of participants engaged in city tourism after their expectation of future economic profits [23]. At the same time, a more prominent role of preventing the spread of COVID-19 is to provide tourism participants with an ideal expectation of future sustainable benefits [29].

The classical theory of expectation motivation proposed by Vroom [5]. His Expectancy theory involves in the field of industrial and organizational psychological research. In the tourism industry, some researchers use his framework to analyze tourism product suppliers' motivations for destination image improvement, economic promotion, community harmony[30]. During this study, through the search of literature achievements, the author found that there was no clear application of Expectancy theory in the field of analyzing behave actively deal with unexpected negative events by using NAM theory. However, after reviewing on this NAM theory and other relevant theories, the author found that the two theories might be synergized. Expectancy theory is applied to explain the process by which individuals make decisions about various behavioural choices. The framework includes three different constructs: valence, instrumentality, expectancy. These three constructs determine the motivations that guide specific behaviours. First component is valence, which it determines to some extent the driving force or attractiveness of the specific outcome. Second component is instrumentality, it mainly means that the more effort you put in, the more likely you are to achieve the desired outcome. Expectancy is the third component of Expectancy theory, which is the perception that a certain amount of performance will lead to the desired result. The more effort you put in, the more likely you are to get desired results. Finally, people believe that good expectations lead to positive actions or intentions. In the study of Keshavarz \& Karami, this theory was applied to predict how hard individuals support on their environmental protective beliefs with respect to the effectiveness of individuals' performance. How hard individuals' work were affected by the effort invested under the spread of COVID-19, whereas effectiveness with regards to how the effort should ultimately ensure the desired results[7]. So, the framework is expressed as follows:

motivational force of practitioner's intention $=$ Valence $\times$ Instrumentality $\times$ Expectancy

In the equation, these three components are examined separately and then determine a motivational force together. However, the study suggests that these three components should be treated with in a chain of causal influences, leading to motivated intention that are conducive to behave actively prevent COVID-19. Since Expectancy theory was put forward, there have been many explanations. The lack of clarity with explaining the interactions between these constructs of motivational force can prompt researchers to analyze how each construct affects other constructs. However, testing the construct between causal relationships is often done. So, the above causal chain is supposed to be like this:

Valence $\rightarrow$ Instrumentality $\rightarrow$ Expectancy $\rightarrow$ Motivational force

In this case, the valence is at the beginning of this chain, which is appeared by a local tourism practitioner's value for some particularly goals, goals include the desired things for earning an ideal tourism livelihood income to survive the pandemic safely. Then this force is lead to instrumentality, which shows that the more efforts on proactively carrying out personal hygiene protection. The 
faster tourism recovery process is carried out to help mitigating the negative impact of the epidemic on the tourism livelihoods of local residents, Such efforts may not contribute directly to some individuals, but in terms of overall benefits, it is effective for the local tourism industry to recover as soon as possible, underlining indispensable role of individual efforts.

After that, instrumentality is considered to have a positive influence on the expectancy. It leads to local tourism practitioners have this expectation that the more the effort to engage in proactive protective intention, the more impact on reducing the risk of infection. Individual contributions may be small, but they are effective overall, emphasizing the role of effort, then it is assumed that valence and instrumentality have positive influence on ones' expectancy. It is an opinion that behaviours will lead to the desired outcomes. Furthermore, expectancy can affect protective intention of preventing COVID-19. From the discussion of Expectancy theory, three assumptions are put forward:

H4. Valence has a positive effect on instrumentality.

H5. Instrumentality has a positive effect on expectancy.

H6. Expectancy has a positive effect on local tourism practitioners' intention of preventing COVID-19.

\subsection{Convergence of the two theoretical frameworks}

Through a large numbers of literature achievements on personal protective intention research, Burton pointed out that discussions of individual socio-psychological construct are more predictive on personal protective intention than discussions focusing on socio-population demographic background [31]. Variables such as awareness, responsibility, norm, and intention on the proactive protection are empirically related to personal feelings and ways of thinking, and ultimately affect intentions of preventing COVID-19 [32]. Norm activation theory has been clearly confirmed and its effectiveness has been tested [12]. In addition, compared to other theories, its pro-social construct of NAM has led researchers to agree that it has a superior predictive power. However, NAM has been studied along with other well-known attitude theories, such as theory of value-belief-norm by stern [33]. Van and Meertens suggested that the merger of pro-social and rational choice theory can produce higher predictive ability [34]. Park and Ha refined NAM and planned behaviour theory into a single theoretical framework[35]. Their findings support the suggestion of Van and Meertens[34], the model shows a better precision of consumer recycling behaviour than the independent NAM framework.

The successful application of the merged model in interpreting individual's behavioural intention can also demonstrate the validity of NAM. In contrast, adopting the expectancy theoretical framework helps improve the performance of single NAM. However, the Expectancy theory is a research framework that has been widely accepted in the world, there are still some criticisms from researchers[36]. A prominent criticism about this theory is the lack of consideration for social impact[37]. By merging expectations theory with the norm activation model, it is assumed that this limitation will be reduced. NAM originated from a theory that studies social movements. These measurement items involve individual awareness, responsibility, and personal norm, then they positively impact behavioural intentions to maintain a safe tourism image, which it affects both tourism livelihood of residents and the progress of tourism recovery. The important view is that expectations for restoring normal tourist order and stable tourism income may affect ones' eagerness to implement personal hygiene protection measures [38]. Yuan Xinwei et al. considered that personal norms are usually formed by social interaction, but the final decision is made by the ones' expectation [39]. In a word, ones' desired outcome(valence) may affect the amount of the individual's actual effort (instrumentality), they in turn affect the practitioner's perception with the possibility of achieving desired outcomes or performances, and ultimately affect the personal protective norm. Although Expectancy theory measures a narrower range of variables than NAM theory, and it doesn't need to consider the frequency of actions. Improving local tourism practitioners' intentions to prevent COVID-19 requires repeated efforts rather than one-off actions. 
The effective impact of norms is essential to promote broad improvements in personal protective intention. Based on these discussions, the link with the two theories are hypothesized as follows:

H7. Valence positively affects ascription of hazardous responsibility.

H8. Instrumentality positively affects personal protective norm.

The proposed theoretical model includes a total of 7 constructs and 8 hypotheses. The interactive relationships between seven constructs is illustrated in Fig.1.

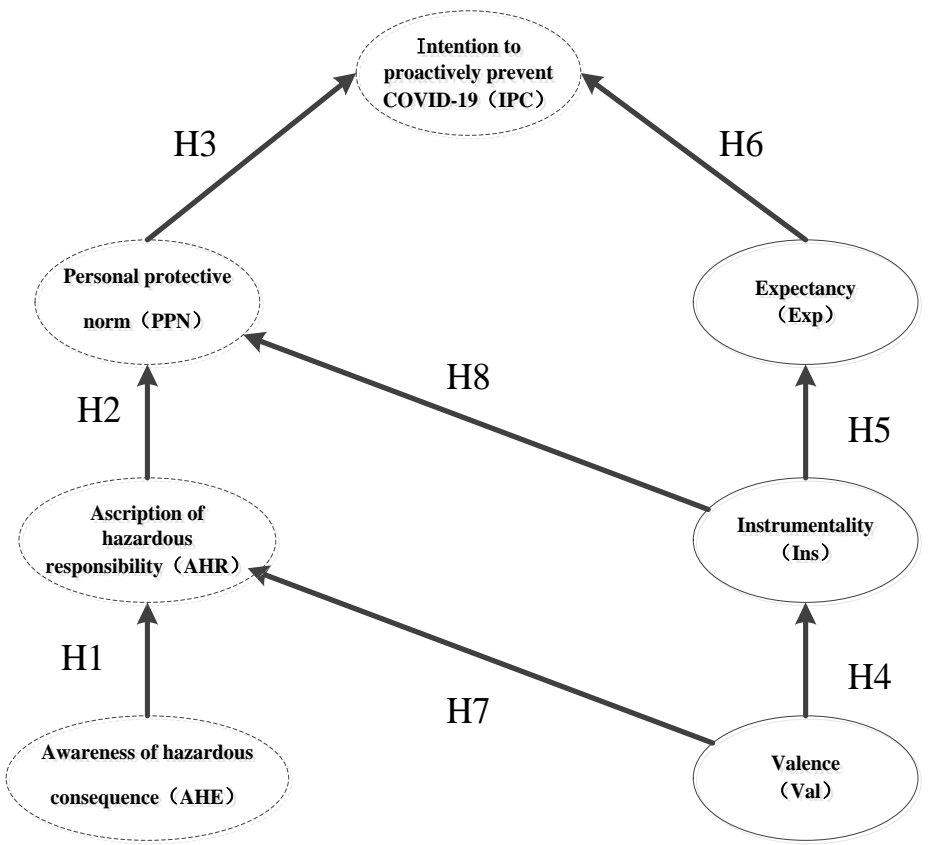

Fig. 1. The proposed research model

Note: constructs with dashed box represent the norm activation model (NMA)

\section{Methodology}

\subsection{Measurement instruments}

The scale and items used in the measurement study was obtained from previous studies validated in various research contexts. The related items are modified to make them best fit the settings of this study. In addition, the manner of the questionnaire used in the field survey has also been discussed to adapt the understanding habits of the sampling population, including some local tourism practitioners with low education level. Its purpose is to make them easier to understand the measurement items, to minimize the amount of invalid responses and reduce potential errors. In this study, five-point Likert scale was used for all latent variables, and there was no recoding problem. The scale of the questionnaire's scores ranged from "extremely disagree" (1) to "extremely agree" (5). Before the final version of the questionnaire was confirmed, the team invited some experienced academics, environmental expert, and undergraduates to conduct pre-tests and assessments. Based on their feedbacks, minor adjustments were made to the formatting, grammar, wording, expression, and visual construct. The final version of the questionnaire was used Chinese, to enable local tourism practitioners who many of them don't have much education can understand or read English. To avoid bias and personal inputs, translators knew nothing about the research beforehand. There are consisted of a cover paragraph at the beginning of the questionnaire, which briefly summarized the purpose and the discipline of this study. Finally, it includes demographic issues, however, sensitive personal issues and their personal contact information are not involved.

\subsection{Study Case}

Zhangjiajie as a world-famous tourist city is famous for its tourist resources. In September 1982, Zhangjiajie National Forest Park became the first national forest park in China. In 1992, the 
Wulingyuan Natural Scenic Area, composed of three tourist attractions in Zhangjiajie, was added to the "World Natural Heritage List" by UNESCO; In February 2004, Zhangjiajie was listed as China's first "Global Geopark". The excellent tourism resources lead the city to choose tourism as its leading industry. Due to the negative impact of COVID-19, these famous tourist attractions were shut down for above 2 months (From the end of January 2020 to the end of April 2020). During the two-month period seriously affected by the epidemic, the entire city basically had no foreign tourists flowing into this city. As a result, the livelihood incomes of many local tourism practitioners have been significantly negatively affected. In order to mitigate the continued damage to the local tourism industry affected by COVID-19 as soon as possible. Some local tourism practitioners have been empowered by government to come back to work. They began to implement the relevant protective measures from the government departments to restore the order of local tourism services. After the COVID-19 in Zhangjiajie, a hygienic and comfortable tourism image can gradually allow local tourism industry to gradually recover. At the same time, they can also obtain a part of tourism livelihood incomes to maintain family expenses.

Local tourism practitioners are the most basic execution force for restoring the tourism image in Zhangiiajie. In the recovery process, the critical power comes from the local tourism practitioners' protective intention of preventing the COVID-19, which it is the scientific basis for policy makers and managers to formulate and modify relevant recovery measures.

\subsection{Data collection}

Data were collected by the author and three students undergraduate major in human geography and urban planning from Agricultural University in 2020. four investigators conducted field surveys in the Zhangjiajie National Forest Park, Wulingyuan, and Tianmen Mountain during April 27, 2020 and April 30. The author provided training and guidance to the investigators before departure. Before issuing the questionnaire, respondents were asked if they are local tourism practitioners in ZhangJiajie, whether they understand the COVID-19, whether their tourism business were affected by the COVID-19, whether they are currently engaged in the tourism, and whether they agree to fill the questionnaire anonymously for academic study, questionnaires are issued only after verbal agreement by local tourism practitioners. The survey samples are local tourism practitioners living around major famous tourist attractions of Zhangjiajie. As the overall identity of the samples are relatively consistent, which provides a relatively homogeneous sampling profile for research and analysis, so the collected data has a high internal validity. 550 responses were gathered statistics to the survey. In order to maintain the credibility of the responses. If more than $10 \%$ of the data in the questionnaire of responses are lost, the questionnaire should be removed. Therefore, 22 responses have been deleted at the beginning. The standard deviation of each response is then calculated to remove the unengaged response, if the case with its value is less than 0.5 was passed in review for patterns exhibiting nonengagement involved the respondents, thus 14 responses are deleted due to showing unengaged performance. As a result, the actual number of valid responses is 514. the questionnaire effective rate was $93.45 \%$. By the way, for a few missing data, this paper uses the series mean to replace, and then further analyzes these valid responses.

\subsection{Sample profile}

Tourism practitioners in tourism attractions of Zhangjiajie National Forest Park, Wulingyuan, and Tianmen Mountain are the research samples. They regard tourism as the main means of livelihood incomes. A sample summary of this study is shown in Table 2.

From table 2: there are 514 valid study samples. $47.67 \%$ of responses are 162 male at the time of the survey, and $52.33 \%$ of responses are female in the valid survey responses, its ratio of male to female is close to 1: 1, which is in line with the local tourism manager' judgment; The average age of 514 valid respondents was 31.79 years old, so the respondents are mainly young people, of which: $25.49 \%$ of respondents are ages from 18 to $24,47.67 \%$ of respondents are ages from 25 to 35 . The majority of respondents are mainly middle education level, of which: $43.78 \%$ of respondents are 
senior high school; $21.79 \%$ of respondents are associate degree; only $17.70 \%$ of respondents have a bachelor's degree or above;

From the source of income, $85.80 \%$ of respondents claim that tourism is the only source of their livelihood income, and only $14.20 \%$ of respondents claim that tourism is not the only source of their livelihood income. From the perspective of the annual income (after tax) obtained from local tourism, $19.84 \%$ of respondents between 3,463dollar to 5,193dollar (24,001 to 36,000 yuan), $35.99 \%$ of respondents between 5,194dollar to 8,655 dollar (36,001 to 60,000 yuan), $13.42 \%$ of respondents between 8,656 dollar to 14,425 dollar (60,100 to 100,000 yuan). It can be inferred that the annual income of most local tourism practitioners is not high, but it is relatively optimistic compared with the income level of other residents who are not engaged in tourism. It can be sure that the sustainable development of city tourism is closely related to the intention of preventing COVID-19. The ratio of effective sample responses to 26 observational items is more than five times, and the number of responses more than 200 samples, which can significantly reduce the risk of non-normal distribution of samples[40], therefore 514 responses cover the main attribute characteristic information of samples.

Table 2. Demographics characteristics of valid responses.

\begin{tabular}{|c|c|c|c|}
\hline Variable & Category & $\begin{array}{c}\text { Distribution } \\
\text { (person) }\end{array}$ & $\begin{array}{c}\text { Valid percentage } \\
(\%)\end{array}$ \\
\hline \multirow{5}{*}{ Gender } & Male & 245 & 47.67 \\
\hline & Female & 269 & 52.33 \\
\hline & Mean & 31.79 & \\
\hline & $16-17$ & 6 & 1.17 \\
\hline & $18-24$ & 131 & 25.49 \\
\hline \multirow[t]{6}{*}{ Age } & $25-35$ & 245 & 47.67 \\
\hline & $36-44$ & 83 & 16.15 \\
\hline & $45-64$ & 41 & 7.98 \\
\hline & over 65 & 8 & 1.56 \\
\hline & primary school and below & 3 & 0.58 \\
\hline & junior high school & 83 & 16.15 \\
\hline \multirow{4}{*}{ Education } & senior high school & 225 & 43.77 \\
\hline & associate degree & 112 & 21.79 \\
\hline & bachelor degree & 85 & 16.54 \\
\hline & graduate degree or above & 6 & 1.17 \\
\hline \multirow{3}{*}{ Source of income } & Tourism is my only source of income & 442 & 85.80 \\
\hline & Tourism is not my only source of income & 72 & 14.20 \\
\hline & Under $\$ 1,731$ & 25 & 4.86 \\
\hline \multirow{7}{*}{$\begin{array}{l}\text { Annual income } \\
\quad \text { (after tax) } \\
\text { exchange rate: } \\
\text { in January 2020 } \\
(\$ 1=¥ 6.9326)\end{array}$} & $\$ 1,732-\$ 3,462$ & 62 & 12.06 \\
\hline & $\$ 3,463-\$ 5,193$ & 102 & 19.84 \\
\hline & $\$ 5,194-\$ 8,655$ & 185 & 35.99 \\
\hline & $\$ 8,656-\$ 14,425$ & 69 & 13.42 \\
\hline & $\$ 14,426-\$ 28,849$ & 38 & 7.39 \\
\hline & $\$ 28,850-\$ 43,274$ & 20 & 3.89 \\
\hline & Over $\$ 43,275$ & 13 & 2.53 \\
\hline
\end{tabular}

\subsection{Tools for analysis}

PASW Statistics 26 and AMOS version 21 were used for data analysis in this paper. In recent research, the combined use of SPSS and AMOS was widely popular, mainly due to the combination of easy-to-visualize and user-friendliness when dealing with conceptual models. In the first stage, the adequacy of the proposed measurement model was analyzed, and the author use confirmatory factor analysis to assess validity and reliability of the proposed model. After achieving the satisfactory fitting results, the second stage is to examine the proposed hypotheses in this study by 
providing path coefficients of different hypothetical relationships. The model comparison amongst the existing model and the model proposed in this study are to verify the constructed model, that is, to establish an adaptive and robust intention model to explain the protective intentions of local tourism practitioners under the spread of COVID-19.

\section{Results}

\subsection{Confirmatory factor analysis (CFA)}

Testing the intention model goodness of fit is the first stage of a two-step approach proposed by Cheung and Chan [41]. Before the CFA, screening of research data to check for possible violations of the proposed eight hypotheses, and the test showed no apparent violation of the assumptions. The value of skewness is between -1 to 1 , and the measurement items do not exceed this value range. The kurtosis value of measurement items are all below the recommended threshold of 3 . Further examination revealed no violations in homoscedasticity, linearity, and multivariate normality.

The CFA factor analysis is the maximum likelihood method, and the tested results show that the proposed model has goodness of fit $\left(\chi^{2}=535.384, \mathrm{df}=253, \mathrm{p}<0.001, \chi^{2} / \mathrm{df}=2.116, \mathrm{IFI}=0.931\right.$, $\mathrm{TLI}=0.910, \mathrm{NFI}=0.877, \mathrm{PGFI}=0.668, \mathrm{RMSEA}=0.061, \mathrm{CFI}=0.930$ ). All the indexes show that the measurement model has good acceptability. According to Gholami et al. [42]. The CFI scores of 514 valid samples are accepted all above 0.90 for the 514 valid samples with 26 observational items. Each latent variable involves multiple measurement items, and in order to verify the internal consistency, composite reliability test is carried out between different latent variables. The test scores show that the values of each indicator are larger than most scholars accepted minimum threshold of 0.70 , and their scores range between 0.851 to 0.952 .

Table 3. AVE, ASV, correlation, reliability, mean and standard deviation.

\begin{tabular}{ccccccccccc}
\hline & AHE & AHR & PPN & IPC & Val & Ins & Exp & AVE & CR & ASV \\
\hline AHE & $0.708^{\mathrm{a}}$ & $0.003^{\mathrm{b}}$ & 0.008 & 0.008 & 0.100 & 0.046 & 0.005 & 0.501 & 0.800 & 0.028 \\
AHR & $0.051^{\mathrm{c}}$ & 0.717 & 0.227 & 0.113 & 0.067 & 0.040 & 0.000 & 0.515 & 0.759 & 0.075 \\
PPN & 0.088 & 0.476 & 0.780 & 0.186 & 0.091 & 0.091 & 0.060 & 0.608 & 0.860 & 0.080 \\
IPC & 0.091 & 0.336 & 0.431 & 0.775 & 0.113 & 0.086 & 0.144 & 0.601 & 0.857 & 0.144 \\
Val & 0.317 & 0.258 & 0.302 & 0.336 & 0.713 & 0.176 & 0.043 & 0.508 & 0.804 & 0.098 \\
Ins & 0.215 & 0.201 & 0.301 & 0.293 & 0.419 & 0.789 & 0.006 & 0.623 & 0.830 & 0.074 \\
Exp & 0.071 & 0.020 & 0.245 & 0.379 & 0.207 & 0.079 & 0.739 & 0.546 & 0.826 & 0.043 \\
Mean & 2.514 & 3.649 & 3.999 & 3.856 & 3.627 & 3.673 & 3.100 & & & \\
SD & 0.702 & 0.955 & 0.696 & 0.721 & 0.693 & 0.737 & 0.889 & & & \\
\hline
\end{tabular}

Note1. Goodness-of-Fit: $\chi 2=535.384, \mathrm{df}=253, \mathrm{p}<0.001, \chi 2 / \mathrm{df}=2.116, \mathrm{RMSEA}=0.061, \mathrm{CFI}=0.930, \mathrm{IFI}=0.931$.

Note2. $\mathrm{AHE}=$ Awareness of hazardous consequence, $\mathrm{AHR}=$ Ascription of hazardous responsibility,

PPN=Personal protective norm, IPC =Intention of preventing COVID-19, Val=Valence,

Ins= Instrumentality, Exp=Expectancy.

a. Composite reliability, that is the square root of average variance extraction.

b. Squared correlations.

c. Correlations.

In Table 3, the validity test of construct was carried out, convergence validity of different latent variables were displayed the average variance extraction (AVE) score was between 0.501 to 0.623 , which was larger than generally acceptable minimum requirement of 0.5 [42]. Finally, the AVE scores are larger than the correlation between the study constructs, providing evidence for discriminant validity[43].

\subsection{Structural equation modeling}

The second stage of two-stage approach proposed by Cheung and Chan [41] was to examine the structural model in the study. Then, structural equation modeling(SEM) analysis was tested the goodness-of-fit with the proposed model, and the results indicated acceptable statistics $\left(\chi^{2}=472.534\right.$, $\mathrm{df}=253, \mathrm{p}<0.001, \chi^{2} / \mathrm{df}=1.868$, IFI=0.785, TLI=0.703, NFI=0.729, PGFI=0.670, RMSEA=0.085, CFI= 0.769). Based on the recommended indices by Hair (2014) [43], the fit results of proposed model also 
showed not satisfactory. Some suggestions referred to the modification indices from AMOS output showed significant improvements about the proposed model. After adding one additional path from "Expectancy" to "Personal protective norm", the goodness-of-fit statistics had been improved significantly. And the originality of the proposed intention model was minimally influenced $\left(\chi^{2}=457.126, \mathrm{df}=247, \mathrm{p}<0.001, \chi^{2} / \mathrm{df}=1.851, \mathrm{IFI}=0.949, \mathrm{TLI}=0.931, \mathrm{NFI}=0.901, \mathrm{RMR}=0.056, \mathrm{GFI}=0.937\right.$, PGFI $=0.660$, RMSEA $=0.041, C F I=0.948$ ). For this purpose, the structural model after the path adjustment was taken as the final model for in-depth analysis and discussion in the study. The aims of the study are to develop a theoretical framework for researchers to explain the local tourism practitioners' protective intention of preventing COVID-19 in the tourist city of China. The adjusted final model was compared with the NAM's original framework $\left(\chi^{2}=201.236, \mathrm{df}=68, \mathrm{p}<0.001\right.$, $\left.\chi^{2} / \mathrm{df}=2.959, \mathrm{IFI}=0.945, \mathrm{TLI}=0.913, \mathrm{NFI}=0.919, \mathrm{PGFI}=0.539, \mathrm{RMSEA}=0.062, \mathrm{CFI}=0.944\right)$. Therefore, the final model showed higher goodness-of-fit than the proposed model mentioned above $\left(\chi^{2} / \mathrm{df}=1.851\right)$ compared to $\left(\chi^{2} / \mathrm{df}=2.116\right)$, and it also showed a better goodness-of-fit than the original NAM $\left(\chi^{2} / \mathrm{df}\right.$ $=2.959)$. Results from the chi-square test of final model and proposed model revealed that there were significant differences between them $\left(\triangle \chi^{2}=78.258, \triangle \mathrm{df}=6, \mathrm{p}<0.01\right)$. Goodness-of-fit of the final model was also relatively better than the original NAM. Moreover, these two models were distinctly different $\left(\triangle \chi^{2}=255.890, \triangle \mathrm{df}=179, \mathrm{p}<0.01\right)$. The final model has a relatively excellent ability to predict local tourism practitioners' protective intention $\left(R^{2}=0.570\right)$, compared with the original NAM model $\left(R^{2}=0.474\right)$ and proposed model $\left(R^{2}=0.547\right)$. From the contrastive results, the final model has a $20.25 \%$ stronger predictive power of intention than the original NAM alone, the comparison summary of structural models is displayed in Table 4.

Table 4. Results of the structural model comparisons.

\begin{tabular}{cccc}
\hline Goodness-of-fit & NAM & Proposed model & Final model \\
\hline$\chi^{2}$ & 201.236 & 535.384 & 457.126 \\
$\mathrm{df}$ & 68 & 253 & 247 \\
$\chi^{2} / \mathrm{df}$ & 2.959 & 2.116 & 1.851 \\
RMSEA & 0.062 & 0.061 & 0.041 \\
CFI & 0.944 & 0.930 & 0.948 \\
IFI & 0.945 & 0.931 & 0.949 \\
TLI & 0.913 & 0.910 & 0.931 \\
NFI & 0.919 & 0.877 & 0.901 \\
PGFI & 0.539 & 0.668 & 0.660 \\
IPC $^{\prime}$ R2(Adjusted) & 0.474 & 0.547 & 0.570 \\
\hline
\end{tabular}

Note 1. Chi-square difference test between the final model and the hypothesized model:

$\triangle \chi^{2}=78.258, \triangle \mathrm{df}=6, \mathrm{p}<0.01$.

Note 2. Chi-square difference test between the final model and the NAM Theory:

$\triangle \chi^{2}=255.890, \triangle \mathrm{df}=179, \mathrm{p}<0.01$.

Note 3. IPC= Intention of preventing COVID-19.

The relationships amongst different constructs were examined as hypothesized. Then, the additional significant path was discovered from the analysis of structural equation modeling.

In Table 5, this study showed the summary of these findings. Awareness of hazardous consequence found to be significantly related to ascription of hazardous responsibility. Ascription of hazardous responsibility found to be significantly in regards to personal protective norm and expectancy. Valence found to be significantly related to expectancy. Expectancy found to be significantly related to personal protective norm. Expectancy and personal protective norm found to be significantly related to the intention of preventing COVID-19. Therefore, while hypotheses 1, 2 and 3 were supported. As expected, the relationships among the NAM constructs were significantly related. Hypotheses 4, 5 and 6 were also supported as expected. Hence, three constructs involved in the Expectancy theory were significantly related. Finally, we need to focus on the two hypothesized relationships which they linked the NAM framework to the Expectancy theory (H7 and H8). While the hypothesis H7 displayed significant relationships and the hypothesis H7 was supported. The hypothesis $\mathrm{H} 8$ was found to be an insignificant related, therefore, hypothesis H8 was also supported. 
Table 5. Standardized parameter estimates of different influence paths of the final model.

\begin{tabular}{|c|c|c|c|c|c|}
\hline & & & Standardized estimate & t-value & Hypothesis \\
\hline H1: AHE & $\rightarrow$ & AHR & 0.205 & $2.018^{*}$ & Supported \\
\hline H2: AHR & $\rightarrow$ & PPN & 0.529 & $4.036^{*}$ & Supported \\
\hline H3: PPN & $\rightarrow$ & IPC & 0.678 & $8.206^{*}$ & Supported \\
\hline H4: Val & $\rightarrow$ & Ins & 0.925 & $5.423^{*}$ & Supported \\
\hline H5: Ins & $\rightarrow$ & Exp & 0.552 & $5.435^{*}$ & Supported \\
\hline H6: Exp & $\rightarrow$ & IPC & 0.142 & $2.341^{*}$ & Supported \\
\hline $\mathrm{H} 7:$ Val & $\rightarrow$ & AHR & 0.615 & $5.516^{*}$ & Supported \\
\hline H8: $\operatorname{Exp}$ & $\rightarrow$ & PPN & 0.281 & $2.542^{*}$ & Supported \\
\hline D1: Exp & $\rightarrow$ & PPN & 0.178 & $1.991^{*}$ & Discovered \\
\hline \multicolumn{3}{|c|}{$\begin{array}{l}\text { Total impact on Intention of } \\
\text { preventing COVID-19: }\end{array}$} & \multicolumn{3}{|c|}{$\begin{array}{c}\mathrm{AHE}=0.207, \mathrm{AHR}=0.412, \mathrm{PPN}=0.739 \\
\mathrm{Val}=0.214, \mathrm{Ins}=0.214, \operatorname{Exp}=0.523\end{array}$} \\
\hline \multicolumn{3}{|c|}{$\begin{array}{l}\text { Goodness-of-Fit Statistics } \\
\text { for the final model: }\end{array}$} & \multicolumn{3}{|c|}{$\begin{array}{c}\chi 2=457.126, \mathrm{df}=247, \mathrm{p}<0.001, \chi 2 / \mathrm{df}=1.857, \mathrm{IFI}=0.949 \\
\text { TLI=0.931, NFI=0.901, PGFI=0.660, RMSEA=0.041, CFI=0.948. }\end{array}$} \\
\hline \multicolumn{3}{|c|}{ Total variance explained: } & \multicolumn{3}{|c|}{$\begin{array}{c}\mathrm{R} 2 \text { of IPC }=0.570, \mathrm{R} 2 \text { of } \mathrm{AHR}=0.287, \mathrm{R} 2 \mathrm{of} \mathrm{PPN}=0.635 \\
\mathrm{R} 2 \text { of Ins }=0.856, \mathrm{R} 2 \text { of } \operatorname{Exp}=0.305 .\end{array}$} \\
\hline
\end{tabular}

Note. ${ }^{*} \mathrm{p}<0.01$

AHE $=$ Awareness of hazardous consequence,

$\mathrm{AHR}=$ Ascription of hazardous responsibility,

$\mathrm{PPN}=$ Personal protective norm,

IPC $=$ Intention of preventing COVID-19,

$\mathrm{Val}=$ Valence,

Ins= Instrumentality,

Exp $=$ Expectancy.

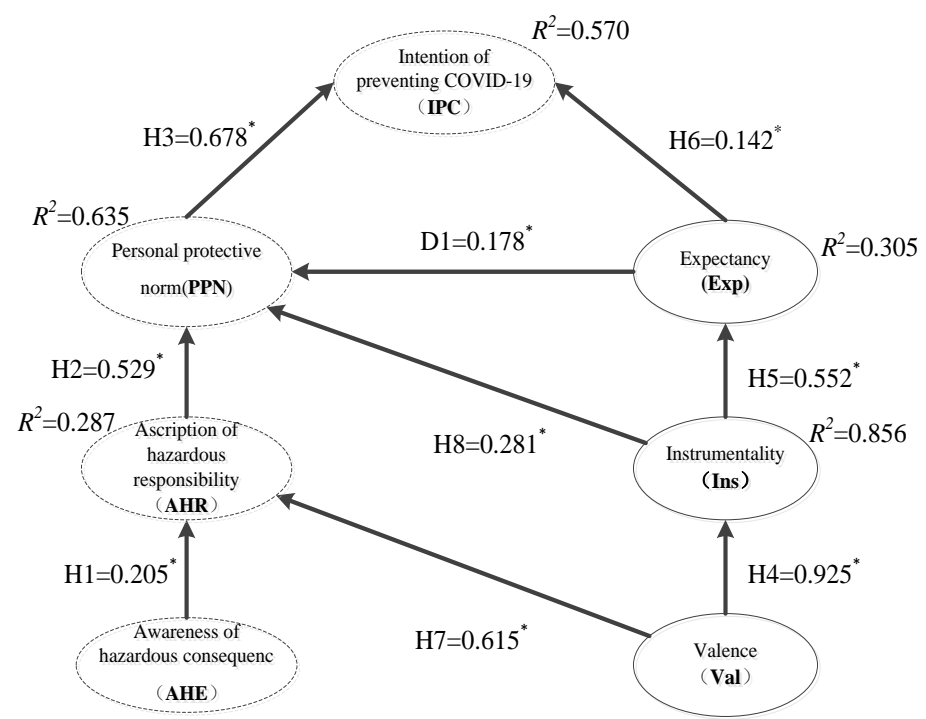

Fig. 2. Results of the final model about the structural equation modeling.

Note: ${ }^{*} \mathrm{p}<0.01$, constructs with dashed box represent the NAM theory.

As mentioned above, the modification indices analysis of different paths related to structural equation modeling indicated that the discovery of one additional relationship was not as initially hypothesis. The study attempted to introduce one additional relationship into the final model, and it will be retained for further discussion with other models in future studies. The additional discovered relationship (D1) based on the proposed model was between ascription of hazardous responsibility and expectancy. Due to the inclusion of the newly discovered paths, compared with the proposed model and norm activation model, the final model was demonstrated improved in the model fit statistics. Hence, this study has opted to retain the discovered path. Figure 2 shows the results of the final model and structural equation modeling analysis. 


\section{Discussion}

This study attempts to fuse the two classical theories in the fields of behavioural intention influenced by pandemic. In the past academic achievements, NAM has a relatively significant predictive ability in the aspect of personal protective intention[44]. In some other areas, Expectancy theory is also used to predict the protective intention in a specific context related to the relevant stakeholders [45]. This study merged the NAM framework with the Expectancy theory to develop a more accurate and robust model, to scientifically predict local tourism practitioners' personal protective intention of preventing COVID-19. Although the original NAM studied intentions after the process of awareness of consequences, attribution of responsibility, personal norm. It also analyzed daily personal protective intention and their aggregate impacts, but it cannot effectively measure individual's "effort". However, the Expectancy theory had been criticized by a part of scholars since it is developed as a theory, its versatility has been affirmed[46]. It can be found that the Expectancy theory focuses on individual's "effort" in the process of application [47]. For example, "The right ascription of hazardous responsibility effectively guides the local tourism practitioners' desired outcomes of successful pandemic preparedness", "the more your expectations, the more positive intentions to achieve the tasks." Hence, the study results of these hypotheses prove the rationality with the merger of these two theories.

In the various constructs of Expectancy theory, the causal relationship expressed by H4, H5, H6 are as significant as the proposed hypothesis. The findings show that the valence (value the local tourism practitioner's personally places on rewards of personal protective intention) is important premise of efforts. That is to say, "efforts" with the personal protective intention may be influenced by the desired outcomes. However, from the perspective of NAM, the activation of protective intention $\mathrm{s}$ is usually predicted by personal norms, ignoring the guidance and expectation of intentions [48].

Since three constructs are added to measure the intentions from the influence factors perspective of "effect" with respect to the Expectancy theory, the predictive power of measurement intention is significantly improved compared with the original NAM, which it supports the researchers emphasizing on how the effort might have a positive promotion to the predictive power of the model. Among the three constructs of Expectancy theory, instrumentality obtained the greatest variance $\left(\mathrm{R}^{2}=0.856\right)$, which clearly supports the positive effort contribution on predictive ability in this study. As expected, when local tourism practitioners feel that their personal intention of preventing COVID-19 may contribute to some improvements of the local tourism recovery, and it has a positive effect on the protective intention to effectively promote more local tourism participants to come back to work.

Based on the findings of Robert et al. who researched the gap between individual's attitude and intention[49], a part of respondents in the questionnaire survey will feel it is should persuade others to care for the safe tourism image, citing that "I am willing to persuade others to protect the safe tourism image of tourist attractions", hinting to their expectation to behavioural intention of preventing COVID-19. We found that these results support a potentially effective new approach to individual protective intentions under the impact of COVID-19. It avoids positioning the proactive protection behaviour and their intentions as a daily requirement or a mundane convention, but promotes its outcomes (The safe tourism image has been improved) to be a desirable pursuit.

The influence relationships among the NAM's constructs showed significant correlations, consistent with Shah et al.'s[50] and San et al.'s results[51]. As expected from the initial hypothesis, there is no significant link between valence and the ascription of hazardous responsibility. The reason for this deviation from initial hypothesis could be due to other peculiar phenomena that cannot be recognized or explained to the study under the impact of special backgrounds and circumstances, it is not the result of the validity on the model itself. One of the possible reasons may be that local tourism practitioners are not very concerned about their social dominance, individual rewards, awareness negative consequences, and utilitarianism. Through the empirical findings, it is proved that the awareness of hazardous consequences, ascription of hazardous responsibility, and personal protective norms are important basis to explain the personal protective intention of 
preventing COVID-19. By the way, compared with some other studies, the conclusions are slightly different. Kiat et.al found that personal protective norm has the highest $R^{2}$ among the variables of the final model[37], whereas personal protective norm was the biggest influencing factor in this empirical study, it further illustrates how behavioural intentions are made in two different contexts. Supposed that daily protective intention under the spread of COVID-19, personal norms drive protective intentions and corresponding actions, and these actions often involve minimal intentions-making. At the same time, protective intention of preventing COVID-19 does not happen frequently, hence, it involves a complex and more deeper intentions-making process. It also shows how the samples feel the positive effect towards the recovery of tourism in this study. The measurement scores of total impacts on behavioural intention (the final model) are further supported as evidence under the spread of COVID-19. In addition, the results suggested personal norms to exert the greatest amount of total impact for various factors affecting protective intention. This is consistent with the conclusions of Bamberg and Moser's (2007), which they considered that personal norm was the most important predictor of individuals' environmental protective intentions[48].

As we hypothesized, the relationships between the two models were proved to be positively significant. Positive H5 was paralleled with previous research conclusions[47]. It can be safely explained that local tourism practitioners who have a positive intention of preventing COVID-19 usually expect to have a good tourism livelihood conditions under spread of pandemic. The relationship of one discovery (D1) helps us to deepen previous discussion of how personal norms play an important role in predicting local tourism practitioners' protective intentions. These analyses and findings had been illustrated not only interpreted that the protective intention started from the awareness of hazardous consequence and valence referred to prevent COVID-19, and it also showed that they can be influenced and then generated.

Finally, testing the final construction details revealed some interesting results. The emergence of one pattern in practice means that local tourism practitioners' actions potentially involved increasing local tourism practitioners' cost of pandemic preparedness and may even significantly reduce their income from tourism, the local tourism practitioners' actual actions and real intentions to prevent COVID-19 are less satisfactory than our initial estimations. This new finding was consistent with Liu et al. [52], Liu et al. deem that lack of money or reducing their previous income levels was one important obstacle to motivate local tourism participants to prevent pandemic whether they are rational or not. Given that the research sample was local tourism practitioners(in fact, they are not very rich), tourism livelihoods obstacles were reflected in their positive protective intention results [52]. Therefore, it is a pragmatic prerequisite for maintaining a safe tourism image to solve the problem of giving financial assistance, to avoid local tourism practitioners' tourist income from obvious negative impacts under the spread of COVID-19.

\section{Conclusions}

This study attempts to fuse the two classical theories in the fields of behavioural intention influenced by pandemic, which it has not been explored in the extant literature. In general, our proposed theoretical framework involving seven constructs and eight causal linkages was satisfactorily positive supported; The four constructs of ascription of hazardous responsibility, personal protective norm, instrumentality, expectancy were found play a significant mediating role within the final model; Although a scarce of existing research efforts to merging NAM and the Expectancy theory into one theoretical framework and by analyzing the intention to proactively prevent COVID-19 in the spread hazard of pandemic context, this study can provide some meaningful implications and should provide a degree of valuable and original insight into this emerging topic. This study helps to further improved the ability to predict behavioral intentions. The final merged model has a $20.2 \%$ better predictive accuracy of intentions than the original NAM alone. The study also discovered that the motivational force of the Expectancy theory significantly influence the protective intention of actively preventing COVID-19, which it comes from the joint impact of valence, instrumentality, and expectancy. In addition, local tourism practitioners are in 
fact not very rich. It is a pragmatic prerequisite for maintaining a safe tourism image to solve the problem of giving financial assistance, to avoid local tourism practitioners' tourism livelihoods income from obvious negative impacts under the spread of COVID-19.

\section{Implications}

The normative activation model has been proposed by Schwartz, and it has been developed and improved, but it has not been widely acceptable in the growing research fields and context changes. Since the introduction of NAM, many studies have validated the rationality of its construction in various context involve the altruistic behavioral intention [48]. It added another research context by demonstrating the application of the model to the local tourism practitioners' intention of preventing COVID-19 under negative impact of pandemic. Hence, the model adds successfully another empirical context. Theoretical implications of this study mainly lie largely in its accuracy in predicting protective intention, its comprehensiveness in theoretical broadening and deepening, it led to achieve the research objectives of this study. In addition, this study expands the framework of the normative activation model and it demonstrated the validity of extending the normative activation model to one another slightly different content, such as the behave personal protective intention of local tourism practitioner engaged in tourism under the spread of COVID-19 in China.

The research results also provided basic ways or approaches of how to improve personal protective intentions, and the main constructs of the final model that need to be manipulated in the context of the resumption of tourism in the context of epidemic preparedness. In practice, local tourism practitioners should first look at awareness of hazardous consequence and valence referred to epidemic preparedness. Han and Kim suggested that awareness and valence of individuals' maintaining a safe tourism image are one of the important factors on the impact of preventive intention [53]. So, in order to restore the tourism industry as soon as possible, some local governments have increased incentives to support the maintenance of tourism's image, and accordingly reduced or exempted the tax or rent of some tourist shops, restaurants, hotels, companies. Through preferential policies, local tourism practitioners are encouraged to come back to work, and ensure that they have long-term earnings expectations for the future development of tourism. Reasonable awareness of hazardous responsibility can stimulate individuals' protective norms [54]. The study further found that the effective implementation of the protective schemes must pay attention to the impact of the protective norms. The using protective norms included comparing individual's behaviour with other local tourism practitioners' norms (i.e. Do you consider that a large proportion of local tourism practitioners in the tourism destination are need to learn relevant personal protective norms?) was much more effective than using those altruism-based measuring items, for example, "Do you have the intentions to follow others on the pandemic preparedness for the tourism livelihoods benefit".

Reasonable expectation was also an effective method. Mihalič refer to "improve the quality of safe tourism image can bring long-term benefits to the local tourism industry"[55] were used successfully to improve individual protective intention. The results of intentions can be explained in personal protective norm and expectancy. Through the influence factor load of the final model (Figure2), personal protective norm was the most important influencer to stimulate the sustainable protective intentions of local tourism practitioners, hence, the focus of activating the behavior intention to prevent COVID-19 should be placed at improving personal protection norms.

Under the spread of COVID-19, the large number of total variables related to the instrumentality interpretation supports the implementational possibility of a reward system for local tourism practitioners in the tourist city. De Young proposed a reward system in maintaining a safe tourism image to improve the possibility of implementing protective behaviours [56]. The reward system for individuals requires participants to increase the investment of capitals and time for tourism recovery, raising the question whether the tourism revenue after pandemic can be higher than the initial high cost of the corresponding prevention behavior. However, it might pose a challenge to the sustainable development of city tourism in the future, but it could still require tourism practitioners have to pay high initial cost. Instrumentality also had another important 
practical contribution to government managers and tourism destinations. It bridged the gap between attitude and intention. Moreover, in theory, these contributions making it more positive for local tourism practitioners to generate intentions of maintaining tourism image. According to the change rules amongst influence factors, it can help managers to improve the personal protective intention, the intention of preventing COVID-19 should needs wider public support and advocacy. What is more, recognizing the change rule of improving behavioral intentions of preventing COVID-19 to maintain the safe tourism image of tourist attractions in Zhangjiajie is also benefits for local tourism practitioners.

Author Contributions: For research articles with several authors, a short paragraph specifying their individual contributions must be provided. Conceptualization, methodology, software, validation, formal analysis, investigation, writing - original draft preparation, project administration, funding acquisition, Hongjiu Tang.

Data curation, Zhaoyin Liu

Funding: This research was funded by GENERAL PROGRAM OF HUNAN NATURAL SCIENCE FOUNDATION, grant number 2020JJ4373. Title: Study on residents' livelihood change and environmental behavior of ecological restoration tourist destination under the policy of Fallow. And the research was also funded by Scientific Research Foundation of Hunan Education Department, grant number 18C0135. Title: The influence of border effect on cross regional governance and coordinated development of urban and rural areas in Changsha-Zhuzhou-Xiangtan City Group. I am the moderator of this research project, and I have received funding from the project for the research work of this paper.

Acknowledgments: Thanks for the support of the research platform from Tourism development and Planning Research Center, Sun Yat-Sen University. We would like to acknowledge the support from all the participated students and the rural cadres. The authors are deeply grateful for useful comments and suggestions from the editor and review experts.

Conflicts of Interest: The authors declare no conflict of interest.

\section{References:}

1. Mbaiwa, J.E.; Stronza, A.L. The effects of tourism development on rural livelihoods in the Okavango Delta, Botswana. Journal of Sustainable Tourism 2010, 18, 635-656.

2. Seetanah, B. Assessing the dynamic economic impact of tourism for island economies. Annals of Tourism Research 2011, 38, 291-308.

3. Schwartz, S.H. Normative Influences on Altruism 1. Advances in Experimental Social Psychology 1977.

4. Stern, P.C. New environmental theories: toward a coherent theory of environmentally significant behavior. Journal of Social Issues 2000, 56, 407-424.

5. Vroom, V.H. Work and motivation. Wiley: New York, 1964; p 6-25.

6. Zhang,Y.L; Zhang,J; Zhang, H.L; Cheng, S.W; Zan, M; Ma, J.H; Sun,J.R; Guo,Y.R. Impact of culture and natural disasters on residents' behaviors toward ecoenvironmental conservation: Sichuan Province case studies. Acta Ecologica Sinica 2014, 34, 5103-5113.

7. Keshavarz, M.; Karami, E. Farmers' pro-environmental behavior under drought: Application of protection motivation theory. Journal of Arid Environments 2016, 127, 128-136.

8. Peng, H.; Zhang, J.; Lin, L.; Tang, G.; Yan, B.; Xiao, X.; Han, Y. Eco-efficiency and its determinants at a tourism destination: A case study of Huangshan National Park, China. Tourism Management 2017, 60, 201-211.

9. Schwartz, S.H. An overview of the Schwartz theory of basic values. Online readings in Psychology and Culture 2012, 2, 2307-2919.

10. Botetzagias, I.; Dima, A.; Malesios, C. Extending the Theory of Planned Behavior in the context of recycling: The role of moral norms and of demographic predictors. Resources, Conservation and Recycling 2015, 95, 58-67.

11. Yu, Z.N; Tan,Y.Z; Lian, K; Wu,C.F. The Credibility of Fallow System for Heavy Metal-contaminated Farmland: A Study Based on Farmers' Perceptions. Chinese Farm Economy 2019, 03, 96-110.

12. Onwezen, M.C.; Antonides, G.; Bartels, J. The Norm Activation Model: An exploration of the functions of anticipated pride and guilt in pro-environmental behaviour. Journal of Economic Psychology 2013, 39, 141-153. 
13. Agliardi, E.; Agliardi, R. Financing environmentally-sustainable projects with green bonds. Environment and Development Economics 2019, 24, 608-623.

14. Olya, H.G.T.; Akhshik, A. Tackling the Complexity of the Pro-environmental Behavior Intentions of Visitors to Turtle Sites. Journal of Travel Research 2018, 58, 313-332.

15. Michel-Guillou, E.; Moser, G. Commitment of farmers to environmental protection: From social pressure to environmental conscience. Journal of Environmental Psychology 2006, 26, 227-235.

16. Hopper, J.S. Having it all? The implications of public health and environmental protection partnerships in the American states. Environmental Policy and Governance 2018, 29, 35-45.

17. Schwartz, S.H.; Boehnke, K. Evaluating the structure of human values with confirmatory factor analysis. Journal of Research in Personality 2004, 38, 230-255.

18. Menzel, S.; Bögeholz, S. Values, beliefs and norms that foster Chilean and German pupils' commitment to protect biodiversity. International Journal of Environmental \& Science Education 2010, 5, 31-49

19. Montada, L.; Kals, E. Political implications of psychological research on ecological justice and proenvironmental behaviour. International Journal of Psychology 2000, 35, 168-176.

20. Han, H. The norm activation model and theory-broadening: Individuals' decision-making on environmentally-responsible convention attendance. Journal of Environmental Psychology 2014, 40, 462-471.

21. Kaiser, F.G.; Hübner, G.; Bogner, F.X. Contrasting the Theory of Planned Behavior with the Value-Belief-Norm Model in Explaining Conservation Behavior 1. Journal of Applied Social Psychology 2005, 35, 2150-2170.

22. Gnoth, J. Tourism motivation and expectation formation. Annals of Tourism Research 1997, 24, $283-304$.

23. Westerberg Vanja; Jacobsen Jette Bredahl; Robert, L. The case for offshore wind farms, artificial reefs and sustainable tourism in the French mediterranean. Tourism Management 2013, 34, 172-183.

24. Liere, K.D.; Dunlap, R.E. Moral Norms and Environmental Behavior: An Application of Schwartz's Norm-Activation Model to Yard Burning. Journal of Applied Social Psychology 2010, 8, 174-188.

25. Linley, J.R.; Davies, J.B. Sandflies and tourism in Florida and the Bahamas and Caribbean area. Journal of Economic Entomology 1971, 64, 264-278

26. Catton Jr, W.R.; Dunlap, R.E. A new ecological paradigm for post-exuberant sociology. American Behavioral Scientist 1980, 24, 15-47

27. Dunlap, R.E.; Van Liere, K.D.; Mertig, A.G.; Jones, R.E. New trends in measuring environmental attitudes: measuring endorsement of the new ecological paradigm: a revised NEP scale. Journal of Social Issues 2000, 56, 425-442.

28. Bear, D. Some modest suggestions for improving implementation of the National Environmental Policy Act. Natural Resources Journal 2003, 43, 931-960

29. Finkelstein, R.A.; Feeley, J.C. Cholera. CRC Critical reviews in microbiology 1973, 2, 553-623

30. Buzinde, C.N.; Vogt, C.A.; Andereck, K.L.; Pham, L.H.; Ngo, L.T.; Do, H.H. Tourism students' motivational orientations: the case of Vietnam. Asia Pacific Journal of Tourism Research 2017, 23, 68-78.

31. Burton, R.J. Reconceptualising the 'behavioural approach' in agricultural studies: a socio-psychological perspective. Journal of Rural Studies 2004, 20, 359-371.

32. Best, H.; Mayerl, J. Values, beliefs, attitudes: An empirical study on the structure of environmental concern and recycling participation. Social Science Quarterly 2013, 94, 691-714.

33. Stern Paul C; Thomas Dietz; Troy Abel; Gregory A. Guagnano; Linda Kalof A Value-Belief-Norm Theory of Support for Social Movements: The Case of Environmentalism. Human Ecology Review 1999, 6, 81-97

34. Van Vugt, M.; Van Lange, P.A.; Meertens, R.M. Commuting by car or public transportation? A social dilemma analysis of travel mode judgements. European Journal of Social Psychology 1996, 26, 373-395.

35. Park, J.; Ha, S. Understanding consumer recycling behavior: Combining the theory of planned behavior and the norm activation model. Family and consumer sciences research journal 2014, 42, 278-291.

36. Chopra, K. Vroom's expectancy theory to motivate academic library users in India using grounded theory approach. Global Knowledge, Memory and Communication 2019, 68, 300-322.

37. Kiatkawsin, K.; Han, H. Young travelers' intention to behave pro-environmentally: Merging the value-belief-norm theory and the expectancy theory. Tourism Management 2017, 59, 76-88.

38. Alsnih, R.; Hensher, D.A. The mobility and accessibility expectations of seniors in an aging population. Transportation Research Part A: Policy and Practice 2003, 37, 903-916. 
39. Yuan, X.; Olfman, L.; Yi, J. How do institution-based trust and interpersonal trust affect interdepartmental knowledge sharing? Information Resources Management Journal 2016, 29, 424-451.

40. Liutikas, D. The manifestation of values and identity in travelling: The social engagement of pilgrimage. Tourism Management Perspectives 2017, 24, 217-224.

41. Cheung, M.W.; Chan, W. Meta-analytic structural equation modeling: a two-stage approach. Psychological Methods 2005, 10, 40.

42. Gholami, M.H.; Asli, M.N.; Nazari-Shirkouhi, S.; Noruzy, A. Investigating the influence of knowledge management practices on organizational performance: an empirical study. Acta Polytechnica Hungarica 2013, 10, 205-216

43. Hair, J.F.; Black, W.C.; Babin, B.J.; Anderson, R.E. Exploratory factor analysis. Multivariate data analysis, 7th Pearson new international ed. 7ed.; Pearson Education: Harlow, UK, 2014; p

44. Zhang, B.; Lai, K.; Wang, B.; Wang, Z. From intention to action: How do personal attitudes, facilities accessibility, and government stimulus matter for household waste sorting? Journal of Environmental Management 2019, 233, 447-458.

45. Pham, T.H.; Nguyen, T.N.; Phan, T.T.H.; Nguyen, N.T. Evaluating the purchase behaviour of organic food by young consumers in an emerging market economy. Journal of Strategic Marketing 2018, 27, 540-556.

46. Parijat, P.; Bagga, S. Victor Vroom's expectancy theory of motivation-An evaluation. International Research Journal of Business and Management 2014, 7, 1-8

47. Chiang, C.; Jang, S.S. An expectancy theory model for hotel employee motivation. International Journal of Hospitality Management 2008, 27, 313-322.

48. Bamberg, S.; Möser, G. Twenty years after Hines, Hungerford, and Tomera: A new meta-analysis of psycho-social determinants of pro-environmental behaviour. Journal of Environmental Psychology 2007, $27,14-25$

49. Robert L, Shrigley; Thomas R. Koballa Jr; Ronald D. Simpson Defining attitude for science educators. Journal of Research in Science Teaching 2010, 25, 659-678.

50. Shah, S.I.U.; Abd Rahim, N. Effect of ethical climate on corporate financial performance in Pakistan: An application of confirmatory tetrad analysis (CTA-PLS) approach. Journal of Studies in Social Sciences and Humanities 2019, 5, 53-67

51. Héctor San Martín; Angel Herrero; Maria Del Mar Garcia De Los Salmones An integrative model of destination brand equity and tourist satisfaction. Current Issues in Tourism 2019, 22, 1992-2013.

52. Liu, C.; Marchewka, J.T.; Lu, J.; Yu, C. Beyond concern-a privacy-trust-behavioral intention model of electronic commerce. Information \& Management 2005, 42, 289-304.

53. Heesup, H.; Jongsik, Y.; Wansoo, K. Youth travelers and waste reduction behaviors while traveling to tourist destinations. Journal of Travel \& Tourism Marketing 2018, 35, 1119-1131.

54. Harland, P.; Staats, H.; Wilke, H.A. Explaining Proenvironmental Intention and Behavior by Personal Norms and the Theory of Planned Behavior1. Journal of Applied Social Psychology 2010, 29, 2505-2528.

55. Tanja., M. Environmental management of a tourist destination: A factor of tourism competitiveness. Tourism Management 2000, 21, 65-78.

56. De Young, R. Changing behavior and making it stick: The conceptualization and management of conservation behavior. Environment and Behavior 1993, 25, 485-505. 